(RESEARCH ARTICLE)

\title{
Plant growth promoting Rhizobacteria: Increase of vegetative and roots biomass in Portulacaria afra
}

\author{
Prisa Domenico * \\ CREA Research Centre for Vegetable and Ornamental Crops, Council for Agricultural Research and Economics, Via dei \\ Fiori 8, 51012 Pescia, PT, Italy.
}

Publication history: Received on 29 January 2020; revised on 04 February 2020; accepted on 06 February 2020

Article DOI: https://doi.org/10.30574/gscarr.2020.2.2.0005

\begin{abstract}
In this study, the ability of PGPRs to improve the growth and rooting of Portulacaria afra in pots was evaluated. Portulacaria afra is an interesting plant from a medicinal and ornamental point of view, but it shows some difficulties in the early stages of cultivation. The two experimental groups in cultivation were: i) group without beneficial microorganisms (CTRL) (peat 60\% + pumice 30\% + chabazite 10\%), irrigated with water and substrate previously fertilized; ii) group with beneficial micro-organisms (PGPR) (peat 60\% + pumice 30\% + chabazite 10\%), irrigated with water and substrate previously fertilized, (1,5g TNC Bactorr ${ }^{S 13}$ per litre of soil). The microorganisms in TNC ${ }^{513}$ Bactorr were: Bacillus amyloliquefaciens, B. brevis, B. cirulans, B. coagulans, B. firmus, B. halodenitrificans, B. laterosporus, B. licheniformis, B. megaterium, B. mycoides, B. pasteuri, B. polymixa, B. subtilis $\left(1.3 \times 10^{11} \mathrm{cfu} / \mathrm{Kg}\right)$. All plants treated with Plant Growth Promoting Rhizobacteria (PGPR) showed a significant increase in the agronomic parameters analysed compared to the untreated control (CTRL), both in Portulacaria afra and in Portulacaria afra variegated. The results show that microorganisms are able to improve the absorption of water and nutrients by increasing the agronomic and physiological characteristics of plants. Very interesting aspects to improve agronomic quality, especially for those who cultivate plants from particular environments and that are poorly adapted to our climates and cultivation methods.
\end{abstract}

Keywords: Succulent plants; Sustainable applications; Portulacaceae; Rhizosphere; PGPR

\section{Introduction}

The genus Portulacaria includes shrubs or small trees with a much ramified trunk, sessile leaves, pale green, peduncolate, inconspicuous pink flowers pink fruit with a diameter of 2-6 mm. In nature, it is very similar to Crassula ovata. There are 2 variegated forms and tricolor cultivars. Distributed mainly in the regions of Mozambique and the Republic of South Africa [1]. The Portulacaria afra L. belongs to the Didereaceae (formerly Portulacaceae) and is commonly called in South Africa also elephant food. It has small succulent leaves and can reach $5 \mathrm{~m}$ in height with the characteristics of a large woody shrub or a small tree [2,3]. The branches have dichotomous branches and the leaves are opposite each other and can last at least one growing season or more [4, 3]. P. afra is spread over an area of about 2 million hectares [5] in the eastern and south-eastern Cape and in some areas represents $90 \%$ of the population. It does not withstand frost but can also be found in cold regions due to its resilience due to population density. The Portulacaria afra is a very important plant in arid environments as it ensures the maintenance of soil moisture after rainfall [6], and promotes the growth of seedlings of subtropical tree lines [7]. It is also tolerant of drought as it can switch from C3 photosynthesis to CAM in low rainfall conditions $[8,9]$.

Plants have the ability to influence soil bacterial communities by producing root exudates specific to the plant species grown. Microorganisms are able to use these substances for their multiplication and are crucial for plant biology by

\footnotetext{
${ }^{*}$ Corresponding author

E-mail address: domenico.prisa@crea.gov.it
} 
producing substances with a similar action to plant hormones that induce cell differentiation, root development and changes in root hair growth [10]. Root colonization by microorganisms can initiate a symbiosis as the beginning of a disease [11].

The micro-organisms in the rhizosphere are decisive in the growth and defence of plants. Rhizobacteria can be classified into extracellular (ePGPR) organisms that live mainly in the rhizosphere and intracellular (iPGPR) organisms that colonize the internal structures of the root. Several Plant Growth Promoting Rhizobacteria can be present in the soil, the most important of which include Nitrotobacter, Bacillus, Pseudomonas, Azospirillum, Agrobacterium, Burkholderia, Bradyrhizobium, Rhizobium, Frankia, Erwinia, Flavobacterium, Chromobacterium, Caulobacter, Arthrobacter, Allorhizobium, Mesorhizobium [12]. They have the capacity to improve the characteristics and fertility of the soil, thus favouring the cultivation of plants. The colonization of the roots takes place through various mechanisms such as the formation of siderophores, the solubilization of mineral phosphates and potassium, nitrogen fixation, and the production of phytophorons. In order to improve the quality of crops it is certainly necessary today to use microbial inoculants able to promote plant growth, control diseases and stimulate soil fertility [13].

In order to improve the quality and quantity of agricultural production without adversely affecting the biodiversity of the agro-system, there is an increasing need to use microbial inoculants that promote plant growth, disease control agents and soil health enhancers. PGPRs also play an important role in improving plant health, resistance to environmental stress, and soil bioremediation [14].

In this study, the ability of PGPRs to improve the growth and rooting of Portulacaria afra in pots was evaluated. Portulacaria afra is an interesting plant from a medicinal and ornamental point of view, but it shows some difficulties in the early stages of cultivation.

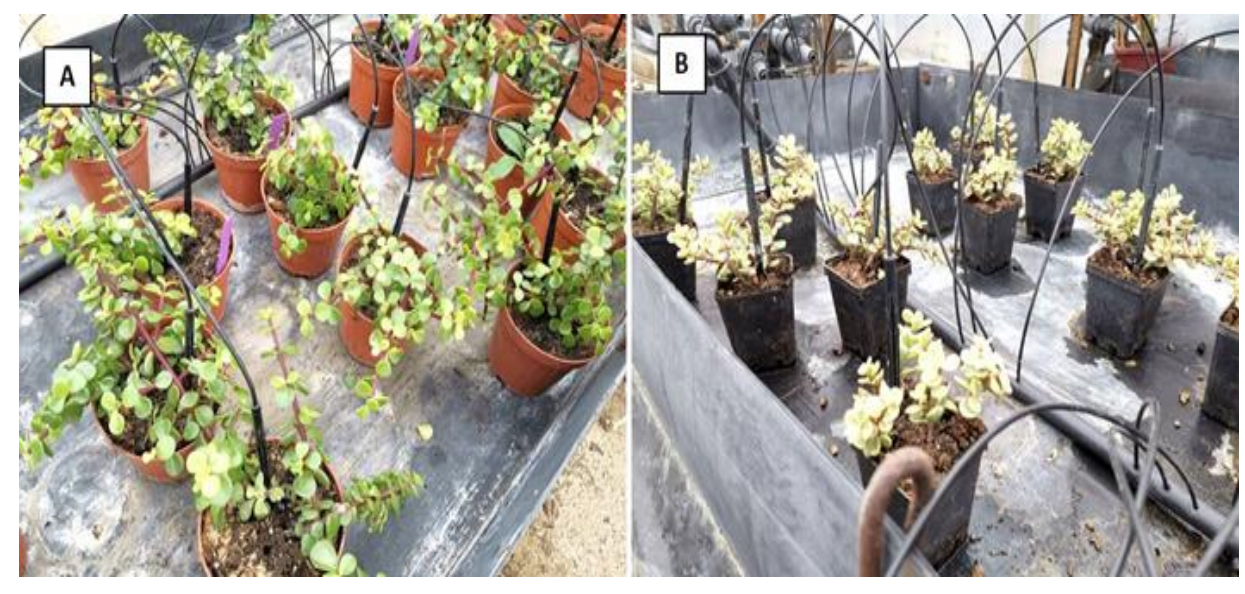

Figure 1 Detail of Portulacaria afra (A) and Portulacaria afra variegated plants (B)

\section{Material and methods}

\subsection{Greenhouse experiment and growing conditions}

The experiments, started in February 2019, were conducted in the greenhouses of CREA-OF in Pescia (Pt), Tuscany, Italy $\left(43^{\circ} 54^{\prime} \mathrm{N} 10^{\circ} 41^{\prime} \mathrm{E}\right)$ on Portulacaria afra and Portulacaria afra variegated plants. The plants were placed in $\emptyset 10 \mathrm{~cm}$ pots; 30 plants per thesis, divided into 3 replicas of 10 plants each. All plants were fertilized with a controlled release fertilizer (4 kg m-3 Osmocote Pro®, 6 months with 190 g/kg N, 39 g/kg P, 83 g/kg K) mixed with the growing medium before transplanting. The two experimental groups in cultivation were:

Group without beneficial micro-organisms (CTRL) (peat 60\% + pumice 30\% + chabazite 10\%), irrigated with water and substrate previously fertilized;

Group with beneficial micro-organisms (PGPR) (peat 60\% + pumice 30\% + chabazite 10\%), irrigated with water and substrate previously fertilized, (1,5g TNC Bactorr ${ }^{\mathrm{S} 13}$ per litre of soil). 
The microorganisms in TNC $\$ 13$ Bactorr were: Bacillus amyloliquefaciens, B. brevis, B. cirulans, B. coagulans, $B$. firmus, $B$. halodenitrificans, B. laterosporus, B. licheniformis, B. megaterium, B. mycoides, B. pasteuri, B. polymixa, B. subtilis (1.3 x $\left.10^{11} \mathrm{cfu} / \mathrm{Kg}\right)$.

The plants were watered 3 times a week and grown for 11 months. The plants were irrigated with drip irrigation. The irrigation was activated by a timer whose program was adjusted weekly according to climatic conditions and the fraction of leaching. On January 20, 2020, the plant height, leaves number, the vegetative and root weight and branches number were recorded. Ten days before the destructive analysis, the chlorophyll content was evaluated (FieldScout CM 1000 Chlorophyll Meter; SPAD index was measured on three leaves of each plant (30 measurements per treatment), net photosynthesis (Pn) (LI-6400XT Portable Photosynthesis System).

\subsection{Statistics}

The experiment was carried out in a randomized complete block design. Collected data were analysed by one-way ANOVA, using GLM univariate procedure, to assess significant $(P \leq 0.05,0.01$ and 0.001$)$ differences among treatments. Mean values were then separated by LSD multiple-range test $(P=0.05)$. Statistics and graphics were supported by the programs Costat (version 6.451) and Excel (Office 2010).

\section{Results}

\subsection{Plant growth}

All plants treated with Plant Growth Promoting Rhizobacteria (PGPR) showed a significant increase in the agronomic parameters analysed compared to the untreated control (CTRL), both in Portulacaria afra and in Portulacaria afra variegated. The results show that microorganisms are able to improve the absorption of water and nutrients by increasing the agronomic and physiological characteristics of plants.

In Portulacaria afra, (Table 1) the plant height was $27.96 \mathrm{~cm}$ in (PGPR), significantly better than $23.98 \mathrm{~cm}$ in untreated control (CTRL). For the number of leaves, 96.40 (PGPR) was better than the control (CTRL) with 75.60 leaves. There was a significant increase in vegetative biomass $121.10 \mathrm{~g}$ (PGPR), compared to the untreated control $105.92 \mathrm{~g}$ (CTRL) (Figure 2A). The treatment (PGPR) for root biomass was also significantly better with $63.60 \mathrm{~g}$ (PGPR), compared to $46.82 \mathrm{~g}$ of the control (Figure 3). There was also an increase in the branche number in PGPR with 19.60, compared to 12.80 in the control (CTRL).

In Portulacaria afra variegated (Table 2), the plant height was $16.28 \mathrm{~cm}$ (PGPR) compared to $12.40 \mathrm{~cm}$ (CTRL). There was an increase in the number of leaves in the thesis treated with Plant Growth Promoting Rhizobacteria with 54.20 leaves per plant, compared to 39.80 in the control thesis. Same trend for vegetative biomass (Figure 2B) where treatment with PGPR with $58.30 \mathrm{~g}$ was significantly better than the untreated control with $48.98 \mathrm{~g}$ and for root biomass where treatment with PGPR was significantly better with $40.24 \mathrm{~g}$ than the control (CTRL) with $36.04 \mathrm{~g}$. Finally also for the number of ramifications the thesis with rhizobacteria showed an increase with 11.20, compared to the control (CTRL) with 8.40 .

Table 1 Evaluation of Plant Growth Promoting Rhizobacteria on agronomic characters on plants of Portulacaria afra

\begin{tabular}{cccccc}
\hline Groups & $\begin{array}{c}\text { Plants } \\
\text { height } \\
\mathbf{( c m )}\end{array}$ & $\begin{array}{c}\text { Leaves } \\
\text { number } \\
\mathbf{( n}^{\circ} \mathbf{)}\end{array}$ & $\begin{array}{c}\text { Vegetative } \\
\text { weight } \\
\mathbf{( g )}\end{array}$ & $\begin{array}{c}\text { Roots } \\
\text { weight } \\
\mathbf{( g )}\end{array}$ & $\begin{array}{c}\text { Branches } \\
\text { number } \\
\left(\mathbf{n}^{\circ}\right)\end{array}$ \\
\hline CTRL & $23,98^{\mathrm{b}}$ & $75,60^{\mathrm{b}}$ & $105,92^{\mathrm{b}}$ & $46,82^{\mathrm{b}}$ & $12,80^{\mathrm{b}}$ \\
PGPR & $27,96^{\mathrm{a}}$ & $96,40^{\mathrm{a}}$ & $121,10^{\mathrm{a}}$ & $63,60^{\mathrm{a}}$ & $19,60^{\mathrm{a}}$ \\
\hline ANOVA & $* *$ & $* *$ & $* *$ & $* * *$ & $* *$ \\
\hline
\end{tabular}

One-way ANOVA; n.s. - non significant; ${ }^{* * * * * *}$ - significant at $\mathrm{P} \leq 0.05,0.01$ and 0.001 , respectively; different letters for the same element indicate significant differences according to Tukey's (HSD) multiple-range test $(P=0.05)$ 
Table 2 Evaluation of Plant Growth Promoting Rhizobacteria on agronomic characters on plants of Portulacaria afra variegated

\begin{tabular}{cccccc}
\hline Groups & $\begin{array}{c}\text { Plants } \\
\text { height } \\
\text { (cm) }\end{array}$ & $\begin{array}{c}\text { Leaves } \\
\text { number } \\
\left(\mathbf{n}^{\circ}\right)\end{array}$ & $\begin{array}{c}\text { Vegetative } \\
\text { weight } \\
\text { (g) }\end{array}$ & $\begin{array}{c}\text { Roots } \\
\text { weight } \\
\text { (g) }\end{array}$ & $\begin{array}{c}\text { Branches } \\
\text { number } \\
\text { (n }\end{array}$ \\
\hline CTRL & $12,40^{\mathrm{b}}$ & $39,80^{\mathrm{b}}$ & $48,98^{\mathrm{b}}$ & $36,04 \mathrm{~b}$ & $8,40^{\mathrm{b}}$ \\
PGPR & $16,28{ }^{\mathrm{a}}$ & $54,20^{\mathrm{a}}$ & $58,30^{\mathrm{a}}$ & $40,24 \mathrm{a}$ & $11,20 \mathrm{a}$ \\
\hline ANOVA & $* * *$ & $* * *$ & $* * *$ & $*$ & $* *$ \\
\hline
\end{tabular}

One-way ANOVA; n.s. - non significant; ${ }^{* * * * * *}$ - significant at $\mathrm{P} \leq 0.05,0.01$ and 0.001 , respectively; different letters for the same element indicate significant differences according to Tukey's (HSD) multiple-range test $(P=0.05)$

Physiological analyses also showed an increase in the net rate of photosynthesis in the thesis treated with rhizobacteria. In fact, for Portulacaria afra (Table 3) the thesis with PGPR showed a net photosynthesis of $17.67 \mu \mathrm{mol} \mathrm{m}^{-2} \mathrm{~s}^{-1}$, compared to $15.66 \mu \mathrm{mol} \mathrm{m}{ }^{-2} \mathrm{~s}^{-1}$ of the control. Same trend for the chlorophyll content, the SPAD analysis of the plants of the thesis with PGPR showed 16.13, while in the control (CTRL) 13.55.

Even in Portulacaria afra variegated (Table 4) the thesis with PGPR showed a photosynthesis rate of $15.62 \mu \mathrm{mol} \mathrm{m}{ }^{-2} \mathrm{~s}^{-}$ 1, compared to $13.56 \mu \mathrm{mol} \mathrm{m}{ }^{-2} \mathrm{~s}^{-1}$ and a chlorophyll content of 11.62 (PGPR), compared to 9.89 of (CTRL).

Table 3 Evaluation of Plant Growth Promoting Rhizobacteria on the physiological parameters of Portulacaria afra

\begin{tabular}{|c|c|c|}
\hline Groups & 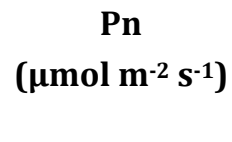 & $\begin{array}{c}\text { Chlorophyll } \\
\text { content } \\
\text { (spad index) }\end{array}$ \\
\hline CTRL & $15,66^{b}$ & $13,55^{b}$ \\
\hline PGPR & 17,67 a & $16,13 \mathrm{a}$ \\
\hline ANOVA & ** & * \\
\hline
\end{tabular}

One-way ANOVA; n.s. - non significant; ${ }^{* * * * * *}$ - significant at $\mathrm{P} \leq 0.05,0.01$ and 0.001 , respectively; different letters for the same element indicate significant differences according to Tukey's (HSD) multiple-range test $(P=0.05)$

Table 4 Evaluation of Plant Growth Promoting Rhizobacteria on the physiological parameters of Portulacaria afra variegated

\begin{tabular}{ccc}
\hline Groups & $\begin{array}{c}\text { Pn } \\
\left(\mu \mathrm{mol} \mathrm{m}^{-2} \mathbf{s}^{-1}\right)\end{array}$ & $\begin{array}{c}\text { Chlorophyll } \\
\text { content } \\
\text { (spad index })\end{array}$ \\
\hline CTRL & $13,56^{\mathrm{b}}$ & $9,89^{\mathrm{b}}$ \\
PGPR & $15,62^{\mathrm{a}}$ & $11,62^{\mathrm{a}}$ \\
\hline ANOVA & $* *$ & $* * *$
\end{tabular}

One-way ANOVA; n.s. - non significant; ${ }^{* * * * * *}$ - significant at $\mathrm{P} \leq 0.05,0.01$ and 0.001 , respectively; different letters for the same element indicate significant differences according to Tukey's (HSD) multiple-range test $(\mathrm{P}=0.05)$. 

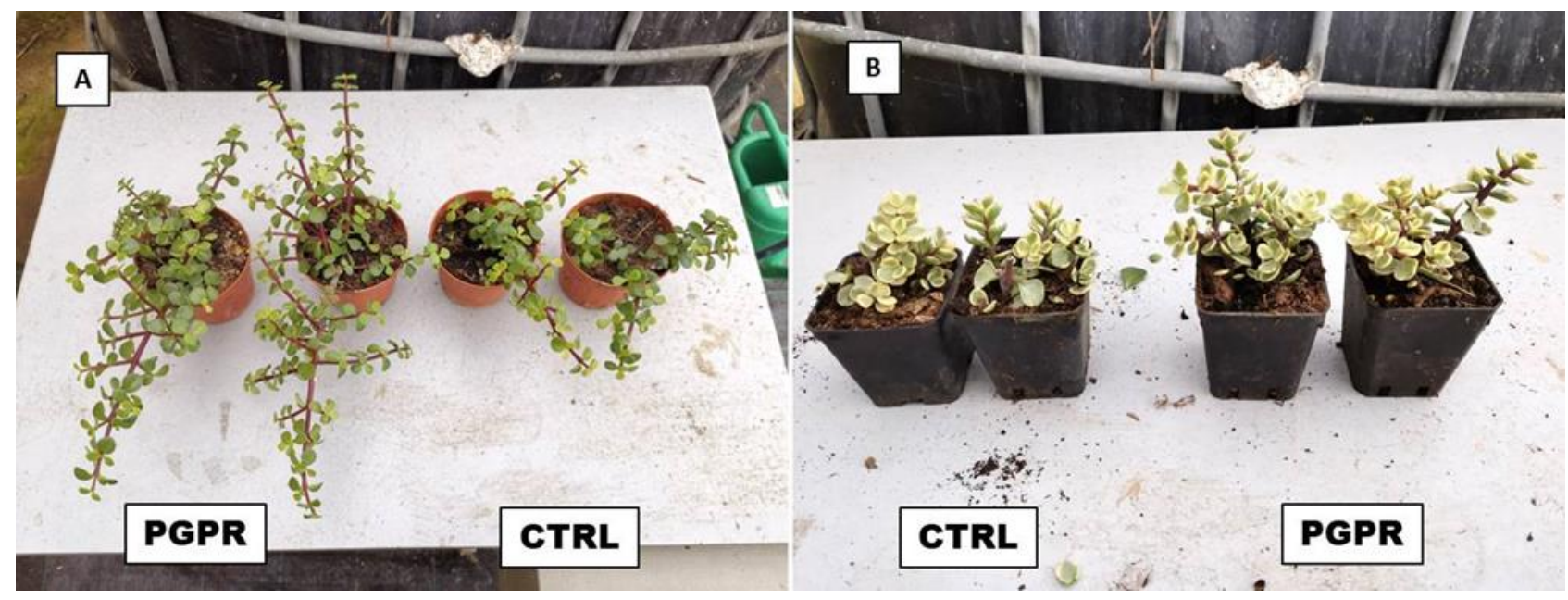

Figure 2 Effect of Plant Growth Promoting Rhizobacteria on vegetative biomass of Portulacaria afra (A) and Portulacaria afra variegated (B). Legend: (CTRL) control; (PGPR) Plant Growth Promoting Rhizobacteria

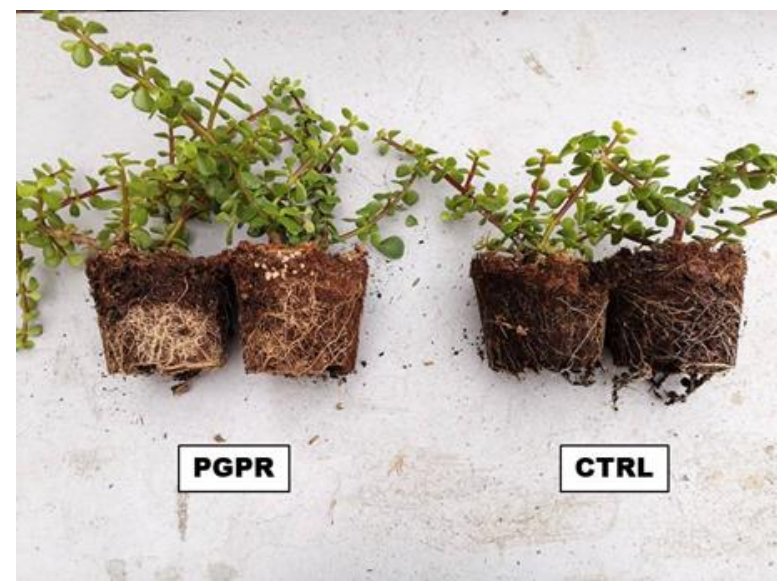

Figure 3 Effect of Plant Growth Promoting Rhizobacteria on roots biomass of Portulacaria afra Legend: (CTRL) control; (PGPR) Plant Growth Promoting Rhizobacteria.

\section{Discussion}

The rhizosphere is a complex habitat, where the plant through the exudates of its roots can promote microbial growth and metabolism. Soil microbiology has a significant influence on plant physiology and growth, but also on protection against deleterious pathogenic microorganisms [15].

In the soil, in fact, you can find a considerable number of microorganisms that perform different functions. Some are beneficial microorganisms, others can cause damage to plants and agricultural production. Among the beneficial microorganisms are the Plant Growth Promoting Rhizobacteria (PGPR), which can live close to the roots or inside specialized cells and are able to stimulate plant growth through various meccanisms. The best known mechanisms include: i) bio-fertilization, i.e. the ability of certain bacteria to make certain nutrients more available; ii) biocontrol, the activity of suppressing certain diseases through the use of certain bacteria; iii) induction of resistance, i.e. the ability of certain bacteria to stimulate plant defences; iv) the production of phytohormones and signal molecules. Rhizobacteria through their activity are able to alleviate the negative effects of stress on plant growth $[16,17,18,19]$. They can produce plant hormones and siderophores, regulating plant metabolism and the availability of nutrients in the soil, in particular iron, copper, zinc and manganese. There are several phytohormones influenced by PGPR, such as abscissic acid, auxins and cytokinins [20]. PGPR can produce several metabolites that can control reactive oxygen species under stress $[21,22]$.

PGPR can also produce antibiotics necessary for symbiosis with their host and for competition with other microorganisms in the rhizosphere [23]. Growth-promoting bacteria can have important effects on plant morphology 
even under stressful conditions. For example, after activation mediated by some root exudates, rhizobium is able to create morphological alterations at root development, in particular the formation of nodules.

In this experiment it is noted above all that the rhizobacteria enriched substrates for the cultivation of Portulacaria afra resulted in a significant increase in all the agronomic parameters analyzed (plant height, number of leaves, vegetative and root biomass, number of branches) and physiological (photosynthesis rate and chlorophyll content). This confirms how the use of PGPR can improve the solubility and availability of nutrients that improve plant growth accordingly.

Indeed, rhizobacteria are able to produce some phytohormones such as auxins and cytokinins [20] and can influence the absorption of some nutrients such as N, P and K as determined for example by Pseudomonas sp. [24]. Furthermore, it has been shown that PGPRs communicate with plants by producing volatile compounds that are able to play an important role in plant growth and systemic resistance induction.

\section{Conclusion}

The test has shown that the use of PGPR can significantly improve the agronomic and physiological quality of Portulacaria afra plants. Rhizobacteria once inoculated into the growing medium improve the uptake of water and fertilizer by the roots and can increase the photosynthetic efficiency of the plants. The rhizosphere represents the soil biotype and can lead to various agronomic consequences such as, for example: i) modification of the soil structure, in fact the microbial population is denser in the rhizosphere than in the soil. This is probably due to the production of gummy substances and the like; ii) nitrogen metabolism, microorganisms determine a balance between mineralization and organic synthesis; iii) solubilisation of mineral elements, the sulphur, iron and phosphorus microorganisms are particularly active in the rhizosphere; IV) plants whose roots are surrounded by rhizospheric microflora are more resistant to pathogenic infections. Very interesting aspects to improve agronomic quality, especially for those who cultivate plants from particular environments and that are poorly adapted to our climates and cultivation methods.

\section{Compliance with ethical standards}

\section{Acknowledgments}

The research is part of the project "Micronaturale": innovative techniques with low environmental impact for the cultivation and defense of plants.

\section{Disclosure of conflict of interest}

The author declares no conflict of interest.

\section{References}

[1] Mills AJ and Robson A. (2017). Survivorship of spekboom (Portulacaria afra) planted within the Subtropical Thicket Restoration Programme. South African Journal of Science, 113, 1/2.

[2] Oakes AJ. (1973). Portulacaria afra Jack. A potential browse plant. Econ. Bot, 27, 413-416.

[3] Baran RJ. (1999). Portulacaria afra the Elephant's food or spekboom.

[4] Guaralnick LJ, Rorabaugh PA and Hanscom Z. (1984). Influence of photoperiod and leaf age on Crassulacean acid metabolism in Portulacaria afra (L.) Jack. Plant Physiol, 75, 454-457.

[5] Mills AJ, Cowling RM, Fey MV, Kerley GIH, Donaldson JS, LechmereOertel RG, Sigwela AM, Skowno AL and Rundel P. (2005). Effect of goat pastoralism on ecosystem carbon storage in semiarid thicket, Eastern Cape, South Africa. Austral Ecol, 30, 797-804.

[6] Van Luijk G, Cowling RM, Riksen MJPM and Glenday J. (2013). Hydrological implications of desertification: Degradation of South African semi-arid subtropical thicket. Journal of Arid Environments, 91, 14-21.

[7] Wilman V, Campbell EE, Potts AJ and Cowling RM. (2014). A mismatch between germination requirements and environmental conditions: Niche conservatism in xeric subtropical thicket canopy species? South African Journal of Botany, 92, 1-6.

[8] Guralnick LJ and Ting IP. (1987). Physiological changes in Portulacaria afra (L.) Jacq. during a summer drought and rewatering. Plant Physiol, 85, 481-486. 
[9] Guralnick LJ and Gladsky K. (2017). Crassulacean acid metabolism as a continuous trait: variability in the contribution of crassulacean acid metabolism (CAM) in populations of Portulacaria afra. Heliyon 3.

[10] Farmer EE and Ryan CA. (1990). Interplant communication: airborne methyl jasmonate induces synthesis of proteinase inhibitors in plant leaves. Proc. Natl. Acad. Sci. USA, 87, 7713-7716.

[11] Boiero L, Perrig D, Masciarelli O, Penna C, Cassán F and Luna V. (2007). Phytohormone production by three strains of Bradyrhizobium japonicum and possible physiological and technological implications. Appl Microbiol Biotechnol, 74, 874-880.

[12] Sorensen J. (1997). The rhizosphere as a habitat for soil microorganisms. In Book Modern soil microbiology. New York, 56, 21-45.

[13] Boehm M, Madden V and Hoitink HAJ. (1993). Effect of organic matter decomposition level on bacterial species diversity and composition in relation to Pythium damping off severity. Applied and Environmental Microbiology, 59, 4171-4179.

[14] Fernando WD, Nakkeeran S and Zhang Y. (2005). Biosynthesis of antibiotics by PGPR and its relation in biocontrol of plant diseases. In PGPR: Biocontrol and Biofertilization, Springer Netherlands, 67-109.

[15] Kennedy AC. (1999). The rhizosphere and spermosphere. In : Principles and applications of soil microbiology, Upper Saddle River, New Jersy, 389-407.

[16] Glick BR, Penrose DM and J Li. (1998). A model for the lowering of plant ethylene concentrations290 by plant growth promoting bacteria. Journal of Theoretical Biology, 190, 63-68.

[17] Prisa D. (2019). Improvement Quality and Content of Pepper and Chilli Nitrates Influenced by the Effective Microorganisms. American Scientific Research Journal for Engineering, Technology, and Sciences (ASRJETS), 53(1), 176-181.

[18] Prisa D. (2019). Rhizobacteria and zeolites for overcoming saline stress in the cultivation of succulent plants. The International Journal of Engineering and Science (IJES), 8(5I), 38-41.

[19] Prisa D. (2019). Biostimulant based on liquid earthworm humus for improvement quality of basil (Ocimum basilicum L.). GSC Biological and Pharmaceutical Sciences, 09(03), 020-025.

[20] Remans RS, Beebe M, Blair G, Manrique E, Tovar and Rao I. (2007). Physiological and genetic343 analysis of root responsiveness to auxin-producing plant growth-promoting bacteria in common344 bean (Phaseolus vulgaris L.). Plant and Soil, 302, 149-161.

[21] Loper J, Henkels MD, Shaffer B, Valeriote F and Gross H. (2008). Isolation and Identification of304 Rhizoxin Analogs from Pseudomonas fluorescens Pf-5 by using a genomic mining strategy. Applied and 305 Environmental Microbiology, 74, 3085-3093.

[22] Jalili F, Khavazi K, Pazira F, Nejati A, Rahmani HA, Sadaghiani HR and Miransari M. (2009). Isolation and characterization of ACC deaminase-producing fluorescent pseudomonads, to alleviate salinity297 stress on canola (Brassica napus L.) growth. Journal of Plant Physiology, 166, 667-74.

[23] Nielsen TH, Sørensen D, Tobiasen C, Andersen JB, Christeophersen C, Givskov M and Sørensen J. (2002). Antibiotic and biosurfactant properties of cyclic lipopeptides produced by fluorescent Pseudomonas spp. Fromt the sugarbeet rhizosphere. Applied and Environmental Microbiology, 68, 3416-3423.

[24] Zabihi HR, Savaghebi GR, Khavazi K, Ganjali A and Miransari M. (2010). Pseudomonas bacteria359 and phosphorous fertilization, affecting wheat (Triticum aestivum L.) yield and P uptake under360 greenhouse and field conditions. Acta Physiologiae Plantarum, 33, 145-152.

\section{How to cite this article}

Prisa D. (2020). Plant growth promoting Rhizobacteria: Increase of vegetative and roots biomass in Portulacaria afra. GSC Advanced Research and Reviews, 2(2), 01-07. 